\title{
Moving cancer immunotherapy forward through the Journal for ImmunoTherapy of Cancer (JITC)
}

\author{
Pedro Romero
}

To cite: Romero P. Moving cancer immunotherapy forward through the Journal for Immunotherapy of Cancer (JITC). Journal of Immunotherapy for Cancer 2020;8:e000001. doi:10.1136/ jitc-2019-000001
Check for updates

(C) Author(s) (or their employer(s)) 2020. Re-use permitted under CC BY-NC. No commercial re-use. See rights and permissions. Published by BMJ.

Department of Oncology, Faculty of Biology and Medicine, University of Lausanne, Lausanne, Switzerland

Correspondence to Pedro Romero;

Pedro.Romero@hospvd.ch
Throughout the 6years of the Journal for ImmunoTherapy of Cancer's (JITC) existence, the field of cancer immunotherapy has changed dramatically. In 2013, when the journal was founded, no programmed death (PD)-1 inhibitors had yet been approved by the Food and Drug Administration (FDA); the first study of CD19 chimeric antigen receptor (CAR) $\mathrm{T}$ cells in ALL patients was just published, and cancer immunotherapy was named the 'Breakthrough of the Year' by Science magazine. Since then, the field has experienced an explosion of developments, with well over 50 FDA-approved cancer immunotherapy indications and nearly $45 \%$ of patients with cancer falling within one of those indications. ${ }^{1}$

It is therefore an exciting time for JITC and the Society for Immunotherapy of Cancer (SITC). The field itself has been growing at a breathtaking pace, making great strides in the realization of SITC's mission-to make cancer immunotherapy a standard of care and the word 'cure' a reality for patients with cancer everywhere. JITC has been a key player in these developments by disseminating groundbreaking results in foundational tumor immunology and clinical cancer immunotherapy. The high value that JITC brings to the oncology field has been recognized by numerous scholarly publishing entities, including Clarivate Analytics, whose designation of an 8.728 journal impact factor has placed JITC within the ranks of the top oncology and immunology peer-reviewed journals.

In the midst of JITC s continued success, I am happy to announce SITC's new partnership with BMJ as JITC's new publisher. With this new transition comes promising new opportunities and developments, both in terms of the scientific content of JITC and the logistical and publishing experiences for authors, reviewers, and readers alike.
Starting in January 2020, JITC will feature two new sections in order to highlight the surge of exciting areas in the field. These will include Immune Cell Therapy and Immune Cell Engineering, edited by Dr Marcela V Maus, and Oncolytic Immunotherapy, with Dr Howard L Kaufman as the Section Editor. The addition of these two sections to JITC's repertoire will allow JITC to rapidly publish the latest top-quality updates in these emerging areas of immunotherapy research and highlight their importance to the field of cancer immunotherapy as a whole. We are looking forward to evaluating the promising research submitted to these new sections, and hope that by placing a greater emphasis on these topics, future work will continue to make strides toward translating these innovative approaches even further into clinical use.

The publishing transition also brings a more streamlined process for authors to submit their work to JITC. For their initial submission, authors will only need to provide part of the overall required submission information for section editors to evaluate their work and begin the review process, as applicable. If the manuscript reaches a revision or acceptance decision after the first round of reviews, authors will then be able to provide the remaining components that are required for manuscript publication. Additionally, payment and discount information for article processing charges will not be required until after an article is accepted. It is our hope that these changes will enable authors to easily and efficiently submit their work to JITC, ensuring we provide faster turnaround times for all submissions while also maintaining the high level of research JITC's readers have come to expect.

Some other exciting changes are also coming down the line for JITC. The new journal site will have the capability to support graphical abstracts. This will enable authors 
to present their work in an engaging, eye-catching way, providing another means for highlighting articles both on the JITC site as well as through various other promotional venues. We will also be introducing additional support and incentive mechanisms for peer reviewers, including a mentorship program and the possibility to claim Continuing Medical Education (CME) credit for time spent reviewing papers. These initiatives will boost the quality of our already world-class peer review network, thereby benefitting authors, our readership, and the cancer immunotherapy field at large.

These changes in the pipeline notwithstanding, the core mission of JITC as a leading tumor immunology and cancer immunotherapy journal will remain the same. Additionally, SITC and BMJ will maintain the current dedication to providing article processing charge discounts to SITC members and other constituents. I cannot wait to see what the next 5,10 , and 20 years bring for the field of cancer immunotherapy, and I know JITC will continue to play a major role in making cancer immunotherapy a standard of care for patients everywhere.

Competing interests None to disclose.

Open access This is an open access article distributed in accordance with the Creative Commons Attribution Non Commercial (CC BY-NC 4.0) license, which permits others to distribute, remix, adapt, build upon this work non-commercially, and license their derivative works on different terms, provided the original work is properly cited, appropriate credit is given, any changes made indicated, and the use is non-commercial. See http://creativecommons.org/licenses/by-nc/4.0/.

\section{REFERENCE}

1 Haslam A, Prasad V. Estimation of the percentage of US patients with cancer who are eligible for and respond to checkpoint inhibitor immunotherapy drugs. JAMA Netw Open 2019;2:e192535. 